\title{
LAS TRANSFORMACIONES DEL CONCEPTO DE AUTORÍA: EL CASO DE LOS APARATOS CRIMINALES ORGANIZADOS DE PODER EN EL CONTEXTO COLOMBIANO
}

\author{
FERNANDO VELÁSQUEZ VELÁSQUEZ*.
}

\begin{abstract}
RESUMEN
El texto analiza las transformaciones impuestas en Colombia por peligrosas corrientes autoritarias que, en el ámbito del Derecho penal, pisotean el Estado de derecho y diluyen centenarias conquistas del Derecho penal liberal. En ese contexto, aborda las discusiones frente al concurso de personas en el delito y, de forma específica, la imputación en el seno de los llamados aparatos criminales organizados de poder, respecto de las cuales advierte su distingo con figuras como la coautoría, el concierto para delinquir, la empresa criminal común o conjunta y la responsabilidad penal del superior. Se aborda, además, la discusión doctrinaria y jurisprudencial colombiana sobre la forma como debe valorarse la conducta punible de quienes delinquen al interior de esos aparatos.
\end{abstract}

\section{Palabras clave}

Estado social y democrático de derecho, corrientes expansionistas, aparatos criminales organizados de poder, autoría, coautoría, inducción, determinación, autoría mediata, autoría mediata en aparatos criminales.

* Ex becario de la Sociedad Max Planck y de la Fundación Alexander von Humboldt; Director del Departamento de Derecho Penal de la Universidad Sergio Arboleda, Bogotá, Colombia. Estre trabajo forma parte de las actividades del autor como miembro del Grupo de Investigación en Ciencias Penales y Criminológicas "Emiro Sandoval Huertas", línea de investigación en Dogmática Penal, y se corresponde con una ponencia presentada el día nueve de julio de 2012, en el "Primer Seminario de Derecho Penal y Criminología. Problemas y tendencias de la Universidad Católica de Colombia: de investigación para el siglo XXI, seminario internacional", que ha sido actualizada. 


\section{INTRODUCCIÓN}

Los vientos que soplan en el Derecho penal actual son los propios de las corrientes expansionistas que, con su ímpetu y arrogancia, pretenden llevarse todo a su paso como si se tratase de un nuevo y mortífero tornado. Por supuesto, lo grave no es que haya ideas distintas y formas diversas de comprender los fenómenos que los estudiosos del Derecho penal deben enfrentar todos los días, como producto de su quehacer académico; lo preocupante es la forma como esas visiones autoritarias, sin ninguna guía teórica, diluyen en la vida práctica las conquistas centenarias del Derecho penal liberal como se observa hoy en países que, como Colombia, se han vuelto expertos en pisotear el Estado de derecho.

En ese contexto, por supuesto, deben ubicarse las "transformaciones" -tal vez sería mejor, desde ya, llamar las cosas por su nombre y hablar de las "regresiones"- observadas en el ámbito del concurso de personas en el delito y, de forma más específica, en tratándose de la imputación en el seno de los llamados aparatos organizados de poder -que se deben denominar "criminales" para evitar confusiones1figura que, al generar un debate interminable, como tantas veces se ha dicho, cobra vida a lo largo de los últimos cincuenta años, en un comienzo en Alemania y luego en España y Latinoamérica.

Por supuesto, las dificultades dogmáticas para encuadrar el asunto no han sido pocas, al punto de que un buen sector de la doctrina opta por ampliar al máximo la noción de autoría mediata para darle cobijo - de aquí ha surgido la concepción de la autoría mediata a través de aparatos criminales organizados de poder en sus diversas manifestaciones-, mientras que otro núcleo de doctrinantes clama por las fórmulas tradicionales en sus diversas variantes también de suyo insuficientes atendidas las características de estos fenómenos; o, en fin, se postula la introducción de nuevas categorías en los textos legales para lograrlo ${ }^{2}$. Incluso, tras el creciente expansionismo del

${ }^{1}$ Cfr. DE LA CUESTA ARZAMENDI, José Luis. El Derecho penal ante la criminalidad organizada. Nuevos retos y límites. En: VALCÁRCEL LÓPEZ, Marta; GUTIÉRREZ ALVIZ Y CONRADI, Faustino (Coord.). La cooperación internacional frente a la criminalidad organizada. Sevilla: Universidad de Sevilla, 2001. p. 88.

${ }^{2}$ Véase, VELÁSQUEZ VELÁSQUEZ, Fernando. La concurrencia de personas en el delito y los aparatos criminales organizados de poder. En: Derecho, Universalidad y conocimiento: Homenaje a Miguel Valadez Reyes. México: Universidad de Guanajuato, 2010. p. 136 y sigtes. y bibliografía allí citada. 
Derecho internacional penal ${ }^{3}$, se acude a otro tipo de construcciones con las cuales se busca arroparlas.

En Colombia, la discusión gana terreno a raíz del sometimiento a la justicia por parte de los criminales paramilitares; un paso más se dio en el año 2010 cuando -sin sentar una línea jurisprudencial clara y concisa, con no pocos equívocos y desaciertos teóricos- la Sala de Casación Penal de la Corte Suprema de Justicia decidió calificar como autores mediatos por medio de aparatos criminales organizados de poder a los jefes de esas estructuras delincuenciales e, incluso, a los líderes políticos adeptos a ellas; ; es más, en otros escenarios judiciales como el del doloroso caso del Palacio de Justicia -resucitado de forma ilegal y tardía-, se ha hecho uso de forma inapropiada y con incontables dislates de dicha construcción teórica ${ }^{5}$.

Por eso, esta reflexión -que se aparta de la construcción propalada a lo largo y ancho del planeta por el brillante Profesor Claus Roxinseñala los hitos fundamentales de la discusión colombiana sobre el asunto para mostrar cómo se pretende violentar los textos legales para darle cabida a institutos que, ni por asomo, contemplan. Con tales miras, en primer lugar, se empieza por deslindar el instituto en examen de otras figuras que se le asemejan; en segundo lugar, aborda la discusión doctrinaria y jurisprudencial vernácula al respecto; además, en tercer lugar, con base en planteamientos

${ }^{3}$ Sobre este fenómeno, PASTOR, Daniel. El Derecho penal del enemigo en el espejo del poder punitivo internacional. En: CANCIO MELIÁ, Manuel y GÓMEZ-JARA DÍEZ, Carlos (Coords.). Derecho penal del enemigo: el discurso penal de la exclusión. Madrid: Edisofer; Buenos Aires-Montevideo: B de F; 2006, vol. 2, p. 475 y sigtes.; VELÁSQUEZ VELÁSQUEZ, Fernando. Justicia internacional penal. Presente y futuro. En: Jueces para la democracia. no. 74, 2012. p. 375 y sigtes.

${ }^{4}$ Cfr. CORTE SUPREMA DE JUSTICIA, SALA DE CASACIÓN PENAL. Sentencia de única instancia de 23 de febrero de 2010, radicado: 32.805, contra Álvaro Alfonso García Romero; en relación com los excesos cometidos en este frente, véase: SUÁREZ LÓPEZ, Carlos Alberto. Aproximación a la problemática de la responsabilidad penal de los jefes de las organizaciones criminales: un estudio de Derecho comparado. En: Huellas. Reflexiones sobre el Derecho penal, no. 72. Bogotá: Fiscalía General de la Nación, julio de 2011. p. 5-62.

${ }^{5}$ Véase VELÁSQUEZ VELÁSQUEZ, Fernando. Los aparatos criminales organizados de poder. En: Cuadernos de Derecho penal no. 4, 2010, p. 173-190. Bogotá: Universidad Sergio Arboleda. [en línea] http:/ /www.usergioarboleda.edu.co/ derecho_penal/cuadernos-de-derecho-penal4.htm [citado en diez de diciembre de 2013]. 
precedentes reitera la postura académica asumida por el autor frente al debate. Al final, en cuarto y último lugar, se consigna la bibliografía consultada.

\section{UNA NECESARIA PRECISIÓN}

El instituto de los aparatos criminales organizados de poder, debe advertirse de entrada, no se puede confundir con cuatro fenómenos que se le asimilan o, en veces, le acompañan: primera, la derivada de la figura que se presenta cuando varias personas mediante un acuerdo común, actúan con división del trabajo criminal, esto es, la coautoría (cfr. arts. 28 y 29 del C. P.); segunda, la que se desprende de la introducción de construcciones delictivas especiales llamadas a castigar a grupos de criminalidad organizada, cuando apenas realizan actividades previas a la ejecución de los delitos para los cuales se asocian, esto es, los eventos de concierto para delinquir (arts. 340 y sigtes. del C. P.).

Así mismo, en tercer lugar, para no caer en los graves yerros de la jurisprudencia nacional ${ }^{6}$-casi siempre proclive a las más extremas teorías subjetivas en estas materias-, el constructo en mención se debe diferenciar de la empresa criminal común o conjunta ${ }^{7}$ de la que habla el actual Derecho internacional penal (Joint criminal enterprise) ${ }^{8}$

${ }^{6}$ CORTE SUPREMA DE JUSTICIA, SALA DE CASACIÓN PENAL, Op. cit., nota 4; CORTE SUPREMA DE JUSTICIA, SALA DE CASACIÓN PENAL. Sentencia de única instancia del 18 marzo de 2010, radicado: 2703, contra el Ex senador Álvaro Araujo Castro. Con razón, pues, SUÁREZ LÓPEZ (Op. cit., p. 60-61) constata la muy borrosa aplicación de esos institutos por parte de dicho ente judicial y advierte que, después de retomar las críticas hechas a ese fenómeno en el plano del Derecho internacional penal, "resulta contraria a principios del Derecho penal sustancial, tales como el de culpabilidad y el de legalidad, y a principios del Derecho penal procesal, tales como el de inocencia y el derecho de defensa".

${ }^{7}$ Para AMBOS, Kai (Principios e imputación en el Derecho penal internacional. 1 ed. Barcelona: Atelier Libros S. A., 2008. p. 81), se debe entender "como un acuerdo común, expreso o tácito, para cometer ciertos actos criminales con un objetivo o finalidad criminal trascendente, como por ejemplo, en el caso de una iniciativa genocida, la destrucción de un grupo en concreto".

${ }^{8}$ Cfr. Ibíd., p. 66 y sigtes.; sin embargo, para OLÁSOLO ALONSO, Héctor (Reflexiones sobre la doctrina de la empresa criminal común en Derecho penal Internacional. En: Indret. Revista para el Análisis del Derecho. 2009, no. 3, p. 4 y sigtes.; OLÁSOLO ALONSO, Héctor. Ensayos de Derecho penal y procesal Internacional. Bogotá: Biblioteca Jurídica Diké; Ministerio de Justicia y del Derecho; Unión Europea: Instituto Iberoamericano de la Haya, 2011. p. 300 y 
y que aparece, por primera vez, en el caso Tadić resuelto por la Sala de Apelaciones del Tribunal Penal para la Ex Yugoslavia, el día quince de julio de 1999 con manifestaciones en la jurisprudencia del Tribunal de Ruanda, para designar crímenes colectivos cometidos por grupos o individuos que actúan en cumplimiento de un designio común de carácter criminal preconcebido con anterioridad o surgido sobre la marcha, sin que tengan que pertenecer a ninguna estructura administrativa, militar, económica o política9; por supuesto, no se necesitan muchos esfuerzos para darse cuenta de que esta construcción académica impera en culturas que no conocen los distingos entre autoría y participación propios de este entorno cultural ${ }^{10}$.

Finalmente, en cuarto lugar, la construcción académica en estudio se debe distinguir del instituto de la responsabilidad penal del superior previsto en los estatutos respectivos y aplicado por tribunales internacionales como los de la Ex Yugoeslavia ${ }^{11}$, Ruanda ${ }^{12}$ y, desde luego, por la Corte Internacional Penal ${ }^{13}$; este evento de estructura omisiva comporta la responsabilidad del superior jerárquico por los actos de sus subordinados, cuando se reúnan ciertos requisitos: a) la existencia de una relación jerárquica entre superior y subordinado; $b$ ) la omisión del superior encaminada a tomar las medidas necesarias

sigtes.) dicha elaboración apenas se alcanza a perfilar con claridad en decisión del 21 de mayo de 2003, caso Milutinovic, del mismo Tribunal.

${ }^{9}$ Cfr. OlÁSOLO ALONSO, Op. cit., nota 8. p. 6.

${ }^{10}$ Puede asumir tres modalidades: a) básica: aquella en la cual los intervinientes en el crimen actúan sobre la base de un designio común; b) sistemática, que comprende casos como los campos de concentración, donde los crímenes los cometen cuerpos militares o administrativos con base en un plan o propósito común; y, la extensiva o forma de empresa en la que intervienen algunos autores materiales que toman parte en los actos, pero van más allá de lo acordado o exceden el plan común, aunque siguen constituyendo una consecuencia natural y previsible de la realización del plan. Cfr. AMBOS, Op. cit., nota 7. p. 68; OLÁSOLO ALONSO, Op. cit., nota 8. p. 7.

${ }^{11}$ Emerge, con toda claridad del art. $7^{\circ}$ del Estatuto. Sobre ello, Cfr. BERTONI, Eduardo Andrés. Autoría mediata por aparatos organizados de poder: Antecedentes y Aplicación Práctica. En: MACEDO, Francisco (Coord.) Los Caminos de la justicia penal y los derechos humanos. Lima: Instituto de Democracia y Derechos Humanos, Pontificia Universidad Católica del Perú, abril de 2007, p. 5. [en línea]. «http:/ / www.dplf.org/uploads/1191421825.pdf» [citado en diez de diciembre de 2013].

${ }^{12}$ Cfr. art. $6^{\circ}$.

${ }^{13}$ Véase art. 28. 
para prevenir los crímenes de sus subordinados o castigarlos cuando ellos se han cometido, y c) el conocimiento del superior de la comisión de los crímenes, o que este tuviera razones para saber que se iban a cometer o ya se habían realizado ${ }^{14}$.

Por supuesto, cuando se intenta diferenciar la figura abordada de esos institutos se observa que ellos, incluida la coautoría -figura disuelta por la jurisprudencia colombiana de las últimas décadas, en contravía del derecho vigente, gracias al engendro expansionista llamado "coautoría impropia"15-, van de la mano de las concepciones subjetivas en materia del distingo entre autor y partícipe dominantes a finales del siglo XIX, que hoy pasan como "modernas" y no suponen ningún avance en estos ámbitos ${ }^{16}$.

\section{LA DISCUSIÓN NACIONAL}

El debate sobre la forma como debe valorarse la conducta punible de quienes delinquen al interior de los aparatos criminales organizados de poder en la discusión vernácula, ha estado sometido -a grandes rasgos- a los mismos vaivenes doctrinarios ${ }^{17}$ y jurisprudenciales ${ }^{18}$ foráneos, aunque con la diferencia de que aquí no se observa el mismo nivel teórico ${ }^{19} \mathrm{y}$ el asunto termina por tener poca trascendencia desde el punto de vista práctico -que no teórico-, porque al autor, al coautor, al instigador y al autor mediato se les impone la misma pena $^{20}$. Al efecto, es importante mirar qué tratamiento se le dio al asunto en vigencia de la pasada legislación y cuál se propone de cara a la presente.

${ }^{14}$ Cfr. AMBOS, Op. cit., nota 7, p. 72.

15 Para la crítica de este instituto, VELÁSQUEZ VELÁSQUEZ, Fernando. Derecho penal, Parte general. 4 ed. Medellín: Editora Jurídica Comlibros, 2009. p. 909 y sigtes.

${ }^{16}$ Ibíd., p. 875.

${ }^{17}$ Un resumen de la misma, en VELÁSQUEZ VELÁSQUEZ, Op. cit., nota 2, p. 136 y sigtes.

18 Para un estudio de las decisiones de los tribunales internacionales, véase OLÁSOLO ALONSO, Ensayos de Derecho penal, Op. cit., nota 8, p. 227 y sigtes, 261 y sigtes.

${ }^{19}$ Deben destacarse, sin embargo, trabajos como los de CADAVID LONDOÑO, Paula. Coautoría en aparatos organizados de poder de carácter delincuencial. Bogotá: Grupo Editorial Ibáñez; Universidad de los Andes, 2013. p. 31 y sigtes. ${ }^{20}$ Así sucede, también, en el derecho alemán. Cfr. CASTILLO GONZÁLEZ, Francisco. Autoría y Participación en el Derecho penal. San José: Editorial Jurídica Continental, 2006. p. 320. 
A. El C. P. de 1980. Esta codificación ${ }^{21}$, como se sabe, no contemplaba la figura de la autoría mediata y sólo se refería al tema en su art. 23 intitulado "autores", mientras que el art. 24 se destinaba a la complicidad. Lo anterior no significa, obvio es decirlo, que la doctrina colombiana de entonces ignorase el asunto, aunque no con la novedad de hoy; en efecto:

1. La coautoría. El autor de este escrito, quien no sólo fue el primero en tratar este asunto en el derecho nacional sino que de entrada rechazó la tesis de la autoría mediata en aparatos criminales organizados de poder, dijo entonces de manera escueta: “... parece evidente que en estos casos se está ante verdaderas hipótesis de coautoría, pues media división del trabajo y se comparte el dominio del hecho" ${ }^{\prime 22}$.

2. La inducción. También, un monografista como Suárez Sánchez planteó que esos casos debían resolverse con base en la figura de la inducción o instigación que, como se dijo, tenía previsión legal ${ }^{23}$.

3. La autoría mediata. A su turno, otro expositor como Posada Echavarría, quien acogió con cajas destempladas otros planteamientos y con puntos de apoyo en extremo discutibles -icomo aquel según el cual quienes abogaban por la tesis de la coautoría defendían la teoría subjetiva!-, postuló como alternativa más idónea la tesis de la autoría mediata aunque tuvo la honradez académica de advertir que "de lege data resulta posible adherir a cualquiera de las tesis que delimitan la calidad de la intervención de quienes actúan mediante aparatos organizados de poder"; incluso admitió la participación criminal, en sus modalidades de complicidad e inducción, en estos $\operatorname{casos}^{24}$.

B. El C. P. de 2000. Una lectura atenta de su articulado muestra que se prevén todas las formas de concurso de personas en el delito aunque no el instituto en examen; además indica que los únicos

${ }^{21}$ Véase LÓPEZ DÍAZ, Claudia. En: AMBOS, Kai. Imputación de crímenes de los subordinados al dirigente. Un estudio comparado. Bogotá: Editorial Temis, 2008. p. 169 y sigtes.

${ }^{22}$ Cfr. VELÁSQUEZ VELÁSQUEZ, Fernando. Derecho penal. Parte general. 1 ed. Bogotá: Temis, 1994. p. 543; VELÁSQUEZ VELÁSQUEZ, Fernando. Derecho penal. Parte general. 3 ed. Bogotá: Temis, 1997. p. 619.

23 SUÁREZ SÁNCHEZ, Alberto. Autoría y Participación. 2 ed., Bogotá: Universidad Externado de Colombia, 1998. p. 237.

${ }^{24}$ Cfr. POSADA ECHAVARRÍA, Plinio. Una visión del «dominio de la voluntad por organización» y su aproximación al derecho penal colombiano. En: Nuevo Foro Penal. Bogotá: Temis-Universidad de Antioquia, 2000. no. 62, p. 38-40. 
eventos en materia de concurso de personas en el delito para los cuales se señala una diminuente punitiva, son la complicidad y el fenómeno del interviniente del art. 30 .

C. La jurisprudencia. La concepción de la autoría mediata en aparatos criminales organizados de poder ha sido acogida después de un largo camino lleno de sobresaltos y de notorias impropiedades dogmáticas, como lo muestra el siguiente recorrido ${ }^{25}$.

1. La tesis de la "coautoría impropia". En efecto, en la Sentencia emitida por la Sala de Casación Penal de la Corte Suprema de Justicia al conocer del crimen de Machuca -cometido por un conocido grupo guerrillero que dinamitó el oleoducto petrolero causando plurales muertes (casi cien) y lesiones personales (treinta)-, ese organismo se negó a debatir los alcances de la figura de la autoría mediata ${ }^{26} \mathrm{a}$ través de los aparatos criminales organizados de poder por estimar que se trataba de un evento de la mal llamada "coautoría impropia" y no de tal fenómeno ${ }^{27}$.

2. La rebuscada concepción de la "coautoría por cadena de mando". Así mismo, todavía en el plano de la coautoría, mediante casación de dos de septiembre de 2009, radicado: 29221 -que dijo desterrar del debate la vieja figura de la "coautoría impropia"-, se acuñó la expresión "coautoría por cadena de mando", en apariencia para

${ }^{25}$ Véase, CADAVID LONDOÑO, Op. cit., nota 19, p. 115 y sigtes., 212 y sigtes., 293 y sigtes., y OLÁSOLO ALONSO, Op. cit., nota 18, p. 276 y sigtes.

${ }^{26}$ Que avaló la Procuraduría de entonces a través de sus voceros. Cfr. FARFÁN MOLINA, Francisco Javier. La masacre de machuca. Autoría mediata a través de aparatos organizados de poder. 1 ed. Bogotá: Instituto de Estudios del Ministerio Público, Imprenta Nacional, 2006. no. 8. p. 10 y 66.

${ }^{27}$ Cfr. CORTE SUPREMA DE JUSTICIA, SALA DE CASACIÓN PENAL. Sentencia de siete de marzo de 2007, Magistrado ponente: Javier Zapata Ortiz, radicado: 23825; reiterada, en sentencia de ocho de agosto de 2007, Magistrada ponente: María del Rosario González de Lemos, radicado: 25974 (caso del fallido atentado criminal contra un reconocido periodista): “. . la jurisprudencia de la Sala considera que quienes imparten las órdenes dentro de una de tales organizaciones tienen la condición de coautores materiales impropios por división de trabajo, y no, de autores mediatos como lo postula el profesor Roxin, de manera que ninguna incidencia tienen tales planteamientos en punto de la conducta aquí analizada"; no obstante, la misma corporación en sentencia de doce de septiembre de 2007, Magistrado ponente: Augusto J. Ibáñez Guzmán, radicado: 24448 (masacre de la Gabarra), se volvió a los planteos consignados en la primera decisión cuyos apartes se transcriben sin ningún aporte adicional. 
designar la elaboración académica en examen ${ }^{28}$. Esta postura fue retomada en la sentencia de tres de diciembre de 2009, radicado: 32672, proceso contra Salvador Arana Sus, oportunidad en la cual también se ordenó compulsar copias para investigar al condenado por los hechos realizados por la organización criminal de la cual se dijo hacía parte ${ }^{29}$.

Esta última elaboración, adviértase, se repite en la sentencia de única instancia contra el exsenador Álvaro Araujo, radicado: 27032, de 18 de marzo de 2010, en la que no obstante no se adopta de forma expresa la tesis de la autoría mediata y, al repetir lo dicho en la sentencia citada en precedencia, se habla de la estructura paramilitar como una verdadera "cadena" en la que se presentan tres elementos: a) existencia de una organización integrada por una pluralidad de personas sustituibles; b) control o dominio de la organización por parte del hombre de atrás y a través de ella de sus integrantes sustituibles; y, c) conocimiento de la organización o aparato de poder y decisión de que sus miembros ejecutan hechos ilícitos.

3. La postura de la autoría mediata. Fue solo en la sentencia contra el ex senador Álvaro Alfonso García Romero de 23 de febrero de 2010, radicado: 32805 -ya citada-, después de advertir que los cambios doctrinarios y jurisprudenciales sobre el asunto llevan a la Sala "a variar su jurisprudencia", que se dijo: “(...) cuando se está ante el fenómeno delincuencial derivado de estructuras o aparatos de poder organizados, los delitos ejecutados son imputables tanto a sus dirigentes -gestores, patrocinadores, comandantes- a título de autores mediatos, a sus coordinadores en cuanto dominan la función encargada-comandantes, jefes de grupo- a título de coautores; y a los

\footnotetext{
${ }^{28}$ Se dijo: "fenómeno de intervención plural de personas en principio articuladas de manera jerárquica y subordinada a una organización criminal, quienes mediante división de tareas y concurrencia de aportes (los cuales pueden consistir en órdenes en secuencia y descendentes) realizan conductas punibles, es dable comprenderlo a través de la metáfora de la cadena. En este instrumento el que se constituye en un todo enlazado, los protagonistas que transmiten el mandato de principio a fin se relacionan a la manera de los eslabones de aquella. En esa medida, puede ocurrir que entre el dirigente máximo quien dio la orden inicial y quien finalmente la ejecuta no se conozcan".

${ }^{29}$ CORTE SUPREMA DE JUSTICIA, SALA DE CASACIÓN PENAL. Sentencias de nueve de diciembre de 2009, radicado: 28779 y doce de mayo de 2010, radicado: 29200, también se ordenó investigar otros delitos en los que pudieron haber incurrido personas vinculadas con grupos paramilitares.
} 
directos ejecutores o subordinados -soldados, tropa, patrulleros, guerrilleros o milicianos-, pues toda la cadena actúa con verdadero conocimiento y dominio del hecho y mal podrían ser amparados algunos de ellos con una posición conceptual que conlleve la impunidad". Se dio, pues, cabida a la autoría mediata en aparatos criminales organizados de poder cuando se trata de "gestores", "patrocinadores" o "comandantes"; no obstante, si se alude a "los coordinadores de la función encargada" se les denomina coautores igual que a los ejecutores o subordinados.

Así mismo, en la sentencia de catorce de septiembre de 2011, radicado: 32000, en el caso del antiguo Director del extinguido DAS, Jorge Aurelio Noguera Cotes, se retomó lo ya dicho para calificar a éste como verdadero autor mediato que actúa valiéndose de un aparato criminal de poder para delinquir ${ }^{30}$.

También, en otras instancias judiciales como la Fiscalía General de la Nación, por medio de la Unidad Nacional de Derechos Humanos y Derecho Internacional Humanitario, se ha reconocido este instituto ${ }^{31}$. De igual forma, lo acoge el Juzgado Tercero Penal del Circuito Especializado de Bogotá al dictar sentencia de primera instancia fechada el nueve de junio de 2010- contra el Coronel Luis Alfonso Plazas Vega, por las desapariciones de algunas personas a raíz de la toma del Palacio de Justicia los días seis y siete de noviembre

${ }^{30}$ CORTE SUPREMA DE JUSTICIA, SALA DE CASACIÓN PENAL. Sentencia de catorce de septiembre de 2011, radicado: 32000, folios 121 y sigtes. A ella, añádase: Auto de 26 de septiembre de 2012, Magistrado Ponente: Luis Guillermo Salazar Otero, radicado: 38250, contra José Gregorio Mangonez Lugo y Omar Enrique Martínez Ossías, en la cual reitera posturas anteriores en las que acoge el evento de la autoría mediata en estos casos (folios 23 y sigtes., 28); Auto de 22 de mayo de 2013, Magistrado Ponente: Gustavo Enrique Malo Fernández, radicado: 40830, contra Ferney Alberto Argumedo Torres (folios 12 y sigtes.); Auto de doce de febrero de 2014, Magistrado Ponente: Gustavo Enrique Malo Fernández, radicado: 40214, contra Miguel Ángel Serrano Ossa, en el que se niega a aplicar la teoría de la autoría mediata en aparatos organizados de poder al entender que el caso encajaba dentro de la llamada "autoría impropia" (folios 20 y sigtes., 36).

${ }^{31}$ En dos procesos diferentes se ha reconocido la tesis de la autoría mediata en tratándose de aparatos organizados de poder: de un lado, en el radicado: 1556, providencia de 13 de mayo de 2005; y, del otro, en el proceso radicado: 2000, providencia de tres de octubre de 2005. Véase: APONTE CARDONA, Alejandro. Jurisprudencia Latinoamericana sobre Derecho penal internacional. 1 ed. Bogotá: Temis, 2008. p. 200-201. 
de 198532; dicho proveído judicial fue confirmado por mayoría mediante un mamotrético escrito - jal parecer confeccionado para competir en la web en tamaño con las sentencias contra Fujimori en el Perú!- expedido por la Sala de Decisión Penal del Tribunal Superior de Bogotá, el día 30 de enero de $2012^{33}$. De igual forma, hizo uso de ese instituto la Sala de Justicia y Paz del Tribunal Superior del Distrito Judicial de Bogotá, mediante sentencia del dos de diciembre de 2010, radicado: RUN 110016000253200680281, en contra de Jorge Iván Laverde Zapata, alias 'El Iguano' ${ }^{34}$.

También, el Juzgado Once Penal del Circuito Especializado de Bogotá, mediante sentencia fechada el 30 de marzo de 2011, radicado: RUN 080013107001 2008-00027-00, condenó al Señor Rodrigo Tovar

${ }^{32}$ Cfr. RUN 11001320700320080002500.

${ }^{33}$ Cfr. TRIBUNAL SUPERIOR DE DISTRITO JUDICIAL DE BOGOTÁ, SALA PENAL. Sentencia de segunda instancia contra el Coronel retirado Alfonso Plazas Vega, radicado: RUN 110010704003200800025 09, treinta de enero 2012, con salvamento del Magistrado Hermes Darío Lara Acuña; en esta decisión el aparato criminal organizado de poder se hace derivar, sin embargo, de una suposición: "Los elementos de juicio que se han expuesto, entendidos dentro de una estructura lógica indiciaria, permiten establecer que existía, entre las fuerzas del Estado que participaron en la recuperación del Palacio de Justicia, una instrucción de exterminio físico total de los miembros del M-19 que realizaron la toma" (folio 566). En otras palabras: ¡el aparato criminal se funda en el hecho (supuesto) de que las Fuerzas del Estado montaron ese andamiaje para perseguir al grupo de criminales que se tomó el Palacio! ¡Nada más lejano de la construcción académica en examen!

${ }^{34}$ Dice la Sala: “... se ha logrado demostrar, no solo la existencia del grupo armado, también el dominio que el postulado tenía sobre el aparato de poder, precisamente por su condición de comandante del frente fronteras, posición que le permitía ejecutar las órdenes que provenían de los superiores e impartir todas aquellas que eran necesarias para desarrollar las políticas del grupo, al margen de la ley, pero con las cuales se identificaba y llevaba a la práctica... Analizados cada uno de los hechos enunciados, se pudo establecer que los ejecutores materiales formaban parte de la estructura respecto de la que ostentaba el poder de mando el postulado JORGE IVAN LAVERDE ZAPATA, circunstancia que sin lugar a dudas lo ubica como autor mediato, especialmente, porque se pudo demostrar que la actuación del postulado consistió en impartir la orden para que se cometieran los homicidios, en cumplimiento de los objetivos de la organización o retransmitirla cuando el mandato provenía de los mandos superiores" (folios 136 y 137, 138-139; cursivas añadidas). Además: TRIBUNAL SUPERIOR DE BOGOTÁ. SALA DE JUSTICIA Y PAZ. Auto de control de legalidad de cinco de octubre de 2012, radicado: RUN 11001-60-00253-2007-52855, contra Ramón María Isaza Arango y otros, Magistrado Ponente: Eduardo Castellanos Roso, folios 338 y ss. 
Pupo alias 'Jorge 40', como "autor mediato responsable de los delitos de homicidio en persona protegida y homicidio agravado, y autor directo de concierto para delinquir", a cuyo efecto se apoyó en la tesis de la autoría mediata en aparatos criminales organizados de poder ${ }^{35}$. Así mismo, el Juzgado 51 Penal del Circuito de Bogotá -que, para acabar de ajustar mal cita las opiniones del suscrito como apoyo de su esperpéntica construcción-, mediante sentencia del 28 de abril de 2011, radicado: 2009-0203, condenó por el entonces inexistente delito de desaparición forzada al General Jesús Armando Arias Cabrales a la pena de treinta y cinco años por los hechos del Palacio de Justicia (1985) e invocó, también de forma incorrecta la susodicha tesis ${ }^{36}$.

35 Dice a folios 22: "podríamos calificar jurídicamente la participación de Rodrigo Tovar Pupo como la de un autor mediato que se vale de toda una estructura a su disposición. En efecto, las AUC constituyen un aparato organizado de poder, con una cadena de mando jerarquizada, en cuya cúpula se encuentra, entre otros, el aquí procesado, en su calidad de comandante del Bloque Norte. Además, el directo ejecutor era perfectamente intercambiable, de tal suerte que si se hubiese negado a cumplir la orden de ejecutar los homicidios, probablemente otro hubiera podido ejecutar ese plan y cumplir el propósito criminal" (cursivas añadidas).

${ }^{36}$ Esa dependencia judicial ["aunque no existe prueba que lo señale como el ejecutor directo de las desapariciones que aquí fueron objeto de averiguación..." (folio 276)], señala lo siguiente: "A tal noción se adscribe el Despacho, teniendo en cuenta que doctrinalmente el dominio de la voluntad en esta forma de imputación, puede desarrollarse en tres modalidades: por coacción, por error y a través de aparatos organizados de poder, última en la que sin duda todos los intervinientes deben responder por la comisión de la ilicitud...Este concepto jurídico permite sostener que en estos casos son los jefes, los dirigentes o los directores, los que de manera exclusiva ostentan el dominio de los acontecimientos, a través de la estructura organizada de poder, lo que finalmente determina su condición de autores mediatos, figura que se caracteriza por la potestad que asiste a quien maneja facultativamente el sistema, no dirigido a una voluntad concreta sino a una indeterminada, ya que cualquiera sea el ejecutor de la orden delictiva, el hecho como tal tendrá existencia" (folio 278). 
D. La doctrina. En la discusión reciente se observan también diversos enfoques:

1. La tesis autoría mediata. En efecto, un grupo de autores [Márquez Cárdenas $^{37}$, Reyes Cuartas ${ }^{38}$, Rivera Llano ${ }^{39}$, López Díaz ${ }^{40}$-quien de forma inconsecuente parte de la sistemática general de Jakobs pero acoge la tesis de Roxin-, Aponte Cardona ${ }^{41}$, Suárez Sánchez ${ }^{42}$ -ahora converso a estas tesis después de defender la concepción de la determinación-, Velásquez Niño ${ }^{43}$ y Suárez López ${ }^{44}$, entre los nacionales, a los cuales se suma el peruano Meini ${ }^{45}$, al esgrimir posturas en las que no se observan construcciones académicas y

${ }^{37}$ Cfr. MÁRQUEZ CÁRDENAS, Álvaro Enrique. La autoría mediata en el Derecho penal. Bogotá: Ediciones Jurídicas Gustavo Ibáñez, 2002. P. 248; MÁRQUEZ CÁRDENAS, Álvaro Enrique. La Autoría mediata: autor detrás de autor en organizaciones criminales: narcotráfico, paramilitares, guerrilleras y mafiosas. En: Diálogos de saberes: investigaciones en Derecho y ciencias sociales, no. 23. Bogotá: Universidad Libre, 2005. p. 20 y 33, afirma que "esta teoría no contradice la normativa vigente en Colombia", aunque al comienzo -de forma contradictoria- reconoce que el art. 29 inc. $1^{\circ}$ del C. P. sólo prevé la figura del autor mediato que se vale de otro como instrumento.

${ }^{38}$ Este autor (cfr. REYES CUARTAS, José Fernando. La autoría mediata con aparatos organizados de poder. En: Derecho Penal y Criminología, no. 75. Bogotá: Universidad Externado de Colombia, 2004, p. 156) pretende obligatorio asumir el planteo propio de la autoría mediata para no propiciar "tratamientos más benignos punitivamente" (!), como si no fuera obvio que en el derecho positivo a los autores en sus diversas modalidades se les impusiera la misma pena; esto, claro está, a no ser que se pretenda emplear dicho instituto para encubrir vacíos probatorios y potenciar formas de responsabilidad objetiva,como de hecho sucede.

${ }^{39}$ Cfr. RIVERA LLANO, Abelardo. Derecho penal posmoderno. 1 ed. Bogotá: Temis, 2005. p. 472.

${ }^{40}$ Véase, LOPEZ DÍAZ, Claudia. El caso colombiano. En: AMBOS, Kai. Imputación de crímenes de los subordinados al dirigente. Un estudio comparado. Bogotá: Editorial Temis, 2008. p. 178 y sigtes.

${ }^{41}$ Véase, APONTE CARDONA, Op. cit., nota 31, p. 203.

${ }^{42}$ Véase, SUÁREZ SÁNCHEZ, Op. cit., nota 23, p. 288.

${ }^{43}$ Para quien, sin ninguna discusión dogmática y político criminal seria, se torna muy fácil acomodar esa construcción en el art. 29 (cfr. VELÁSQUEZ NIÑO, Jorge. La autoría mediata por medio de estructuras organizadas de poder: el caso colombiano. En: Realidades y tendencias del Derecho en el Siglo XXI. Bogotá: Universidad Javeriana/Temis, 2010, Tomo III. p. 279-281).

${ }^{44}$ SUÁREZ LÓPEZ, Op. cit., nota 4, p. 5, 22 y 60.

${ }^{45}$ MEINI MÉNDEZ, Iván Fabio. Problemas de autoría y participación en la criminalidad estatal organizada. En: Nuevo Foro Penal, no. 68. Medellín: Universidad Eafit, 2005. p. 67 y 68. 
político-criminales idóneas y en muchos casos fruto de la intuición, entiende que "el hombre del sofá" y quien esté incardinado en un aparato criminal organizado de tal modo que pueda dar órdenes a personas subordinadas a él y haga uso de esa facultad para la realización de acciones punibles, debe ser tratado como un verdadero autor mediato. Incluso, algunos de ellos, después de hacer trizas el principio de legalidad, afirman que el art. 29 prevé la autoría mediata a través de aparatos criminales organizados de poder de forma expresa ${ }^{46}$.

2. La concepción que opta por la determinación. Otro sector doctrinario, que lidera Hernández Esquivel, luego de entender que la tesis de la autoría mediata no es aplicable en el derecho colombiano se inclina por la determinación ${ }^{47}$.

3. La postura que aboga por la coautoría. A su turno, el autor de este estudio -una vez entrado en vigor el nuevo Código Penal: Ley 599 de 2000- ha insistido en su tesis primigenia pero de forma matizada, para sostener que "el asunto, sin embargo, es en extremo polémico y no se pueden hacer encasillamientos tajantes o absolutos, olvidando las particularidades de cada caso y el punto de partida que se asuma, pues nada impide concebir en un aparato organizado de poder verdaderos fenómenos de autoría mediata -en el sentido en que aquí se entiende-, o casos de inducción; aunque, se repite, en principio se tratará de casos de coautoría si se presentan las exigencias de la misma"48. Esta línea doctrinal ha sido acogida

${ }^{46}$ Así, REYES CUARTAS, Op. cit., nota 38, p. 154; MEINI MÉNDEZ, Op. cit., nota 45, p. 67 y 68; SUÁREZ SÁNCHEZ, Op. cit., nota 23, p. 288 y SUÁREZ LÓPEZ, Op. cit., nota 4, "Aproximación a la problemática de la responsabilidad", p. 60, para quien -apoyado en argumentos de aparente autoridad- "...para ello no es necesaria una reforma legal, pues, como lo ha reconocido la Sala Penal (sic) de la Corte Suprema de Justicia, el artículo 29 del Código Penal admite perfectamente esta interpretación". En otras palabras: este autor parece conferirle poderes de legislador a dicho tribunal y llama "interpretación" a lo que, desde una perspectiva estrictamente hermenéutica, no es más que la postulación de la violación del principio de legalidad de los delitos y de las penas.

${ }^{47}$ Así, HERNÁNDEZ ESQUIVEL. Autoría y participación. En: AA. VV.: Lecciones de Derecho penal, parte general. Bogotá: Universidad Externado de Colombia, 2002. p. 274.

${ }^{48}$ Así, VELÁSQUEZ VELÁSQUEZ, Fernando. Manual de Derecho penal, parte general. 1 ed. Bogotá: Temis, 2002. p. 447-448; VELÁSQUEZ VELÁSQUEZ, Fernando. Manual de Derecho penal, parte general. 2 ed. Bogotá: Temis, 2004, p. 455; VELÁSQUEZ, Fernando. Manual de Derecho penal, parte general. 3 ed. 
por Cadavid Londoño, en su Tesis Doctoral, sin duda la mejor contribución nacional monográfica sobre la materia ${ }^{49}$.

4. La mal llamada "coautoría impropia". Así mismo, como si ese engendro jurisprudencial no hubiese sido desterrado de la ley penal -así sea recordado con frecuencia por jueces subjetivistascomo fue el querer explícito de los legisladores que expidieron el C. P. de 2000, un autor como Sánchez Herrera -luego de asumir de forma correcta la imposibilidad de deducir de la ley vigente la figura en examen- pretende que la mejor solución es esa ${ }^{50}$. En otras palabras: ¡una postura de conveniencia propia de estos tiempos de autoritarismo y de expansión!

5. Otros caminos. Finalmente, Bernate Ochoa -cuya reflexión apunta a los delitos de género- después de calificar la tesis roxiniana como "inaceptable en nuestro medio" 51 , cosa que también hace con las demás propuestas, ensaya el empleo de algunas figuras de la Parte Especial para castigar a quienes delinquen en los ámbitos mencionados al interior de este tipo de aparatos criminales, como el constreñimiento a delinquir y la inducción a delinquir en sus diversas modalidades, pero termina desechándolas por insuficientes, sin asumir una postura clara al respecto; en fin, clama por una reforma

Medellín: Editora Jurídica Comlibros, 2007. p. 450-451, fundamentando mejor su postura y restándole importancia práctica a la discusión, pues "el autor, el coautor, el instigador y el autor mediato se hacen acreedores a la misma pena", p. 451; VELÁSQUEZ VELÁSQUEZ. Op. Cit., nota 15, p. 893 a 895; VELÁSQUEZ VELÁSQUEZ, Fernando. Manual de Derecho Penal. Parte general. 5a ed. Bogotá: Ediciones Jurídicas Andrés Morales, 2013. p. 580.

${ }^{49}$ Véase CADAVID LONDOÑO, Op. cit., nota 19, p. 276 y sigtes, 426 y sigtes. ${ }^{50}$ SÁNCHEZ HERRERA, Esiquio Manuel. La autoría en los aparatos organizados de poder. La situación en la jurisprudencia nacional. En: Huellas. Reflexiones sobre el Derecho penal, no. 72. Bogotá: Fiscalía general de la Nación, 2011. p. 136: “... la tesis de la coautoría impropia, es la que mejor se adapta al caso, toda vez que en nuestro sentir, como bien lo destaca la Corte, el hecho de que los cabecillas dominen y pongan en marcha la maquinaria delictiva, consigan recursos, los administren, los asignen a los planes operativos concretos, tracen políticas de ataques y de selección de objetivos, condicionan per se su autoría. Motivo por el cual no podría hablarse de determinación o inducción".

${ }^{51}$ Cfr. BERNATE OCHOA, Francisco. La imposibilidad de la aplicación de la autoría mediata por dominio funcional de aparatos de poder en el sistema legal colombiano. En: Revista internacional Derecho penal contemporáneo, no. 36, julio-septiembre. Bogotá: Editorial Legis, 2011. p. 10. 
legal en esta materia cuando no por la reformulación de algunas de las propuestas actuales ${ }^{52}$.

\section{REFLEXIONES FINALES}

A esta altura de la exposición bien vale la pena retomar algunas ideas expuestas en otras sedes ${ }^{53}$, para poner punto final en este escrito.

Sin duda, en el derecho colombiano -mientras no se produzca una reforma que incluya directamente el instituto en examen ${ }^{54}-\mathrm{el}$ asunto discutido sólo puede ser abordado a partir de las categorías tradicionales en materia de imputación que, como han sido pensadas para una criminalidad diferente a la que hoy acompaña a las modernas organizaciones sociales hundidas en una creciente globalización económica y asoladas por el terrorismo, deben ser actualizadas y modernizadas.

Acudir a la tesis de la autoría mediata no sólo supone violentar el texto legal sino partir de una construcción sofística y, como lo muestra el Profesor alemán Schild, ambivalente ${ }^{55}$, que supone sin fundamento la existencia de una construcción uniforme para los aparatos criminales organizados de poder cuando las características de cada uno distan de ser uniformes y precisas. Basta con examinar, a título de ejercicio académico, los "grupos de casos" que propone Ambos ${ }^{56}$

${ }^{52}$ Cfr. Ibíd., p. 21 y sigtes.

53 Sobre ello, VELÁSQUEZ VELÁSQUEZ, Op. cit., nota 2, p. 136 y sigtes; VELÁSQUEZ VELÁSQUEZ, Fernando. ¿Los líderes paramilitares: ¿autores mediatos por medio de aparatos criminales organizados de poder? En: Revista de Derecho Penal, Imputación, causalidad y Ciencia-III. Buenos Aires: RubinzalCulzoni, 2011. p. 79 y sigtes.

${ }^{54}$ Recuérdese la postura de BOLEA BARDÓN, Carolina. Autoría mediata en Derecho penal. Valencia: Tirant lo Blanch, 2000. p. 374.

55 Véase, al respecto, lo que señala SCHILD, Wolfgang. Täterschaft. En: KINDHÄUSER, Urs; NEUMANN, Ulfrid; PAEFFGEN, Hans-Ulrich. Nomos Kommentar zum strafgesetzbuch, t. I. 3 ed. Baden Baden: Nomos Verlag, 2010. p. 1062-1063; otras críticas en HEINE, Günter/WEI $\beta E R$, Bettina. Täterschaft. En: SCHÖNKE-SCHRÖDER. Strafgesetzbuch. Kommentar. 29 ed. München: C. H. Beck, 2014. p. 525-526.

${ }^{56}$ Cfr. AMBOS, Kai. Dominio del hecho por dominio de voluntad en virtud de aparatos organizados de poder. tr. Manuel Cancio Meliá. Bogotá: Universidad Externado de Colombia. 1998. p. 32 y sigtes.; AMBOS, Kai. Tatherrschaft durch Willensherrschaft kraft organisatorischer Machtapparate. Eine kristische Bestandsaufnahme und weiterführende Ansätze. En: Goldammer's Archiv für Strafrecht, no. 5. Heidelberg: R. v. Decker, 1998. p. 235 y sigtes. 
para captar que ello es así: no se pueden parificar las estructuras criminales de poder del nacionalsocialismo con las propias de las dictaduras latinoamericanas de los años setenta (Argentina y Chile) o con las imperantes en la antigua República Democrática Alemana; tampoco, para hablar de los delitos cometidos en el seno de aparatos de poder de organizaciones no estatales, es posible asimilar las construcciones propias de los carteles de la droga colombianos -que el mismo profesor alemán se resiste a ubicar en este escenario ${ }^{57}$ - con las de las mafias italianas o con la máquina sanguinaria de terror puesta en escena por los paramilitares patrios. Es más, un análisis detenido de esa postura -cuyos mayores logros se producen en el ámbito de los aparatos organizados de criminalidad estatal ${ }^{58}$ permite concluir que ella se confecciona a partir de la dogmática de la Parte General, para evadir vacíos y/o dudas probatorias, que, recuérdese, se evidencian cuando se examinan las conductas llevadas a cabo valiéndose de o dentro de los aparatos organizados de poder.

Por ahora, pues, para juzgar las conductas ya cometidas se tiene que acudir a las categorías dogmáticas tradicionales alimentadas por construcciones como la del dominio del hecho, sin hacer encasillamientos tajantes o absolutos que olviden las particularidades de cada caso y el punto de partida asumido ${ }^{59}$. Por ello, nada impide concebir en un aparato organizado de poder verdaderos fenómenos de coautoría ${ }^{60}$, de autoría mediata -en el sentido tradicional, antes

${ }^{57}$ Cfr. AMBOS, Kai. Dominio del hecho por dominio de voluntad, Op. cit., nota 56, p. 49: “...también en el caso de los llamados "cárteles de la droga» colombianos difícilmente podrá demostrarse la existencia de una estructura de organización de carácter jerárquico".

${ }^{58}$ Cfr. CASTILLO GONZÁLEZ, Op. cit., nota 20, p. 315.

${ }_{59}$ Cfr. BOLEA BARDÓN, Op. cit., nota 54, p. 370 y 401; JOSHI JUBERT, Ujala. Sobre el concepto de organización en el delito de tráfico de drogas en la jurisprudencia del Tribunal Supremo. En: Anuario de Derecho Penal y Ciencias Penales, tomo XLVIII, Fasc. II, mayo-agosto de 1995. Madrid: Ministerio de Justicia, 1995. p. 657 y sigtes.

${ }^{60}$ Así, GARCÍA VITOR, Enrique. La tesis del «dominio del hecho a través de los aparatos organizados de poder». En: Nuevas formulaciones en las ciencias penales: Homenaje a Claus Roxin. Córdoba: Facultad de Derecho y Ciencias Sociales, Universidad Nacional de Córdoba, 2001. p. 347 y 348; para CASTILLO GONZÁLEZ, Op. cit., nota 20, p. 133, 213, 309 y sigtes., es un caso de coautoría. Por su parte, MUÑOZ CONDE, Francisco y GARCÍA ARÁN, Mercedes (Derecho penal, Parte general, 7 ed., Valencia, Tirant lo Blanch, 2007. p. 448 y sigtes.), después de advertir que es casi imposible encontrar una solución unitaria, hace 
de que se expandiera casi sin límites esta construcción ${ }^{61}-$ o hipótesis de inducción e, incluso, casos de complicidad o de autoría accesoria o paralela.

Sin duda, fuera de los delitos cometidos dentro de la maquinaria criminal, se debe imputar la figura de concierto para delinquir ${ }^{62}$ prevista para combatir grupos de criminalidad organizada y aplicable con independencia de que los plurales agentes realicen o no las conductas para las cuales se concertaron (véase, arts. 340 y ss. del C. P.); con la advertencia, eso sí, de que estas construcciones no se pueden volver tipos penales de captación -donde toda conducta, por inane que sea, queda arropada- o mecanismos que reemplacen a la conspiración propia del Derecho anglosajón que llevan el Derecho penal de autor hasta sus manifestaciones más extremas, como hace una decadente y caprichosa jurisprudencia en esta materia $^{63}$. Esta conclusión se impone, a pesar de que los defensores foráneos de la tesis de la autoría mediata la dejan de lado -cosa en la cual no reparan sus inconsecuentes voceros nacionales-, por estimar que la realización de dicha conducta nada tiene que ver con la conformación del aparato criminal, incluso si se ha nombrado

una triple distinción: en el ámbito de la criminalidad estatal o paraestatal, habla de autoría mediata; para las organizaciones criminales de carácter no estatal, afirma la coautoría; y, en el marco de organizaciones de carácter empresarial, se inclina por la coautoría o la "coautoría mediata". Las distintas posturas sobre la delincuencia en la empresa, en ARAMBURO CALLE, Maximiliano Alberto. La delincuencia en la empresa: problemas de autoría y participación en delitos comunes. En: Nuevo Foro Penal, no. 68. Medellín: Universidad Eafit, 2005. p. 93 y sigtes., p. 93 y sigtes.

${ }^{61}$ Así, ARAMBURO CALLE, idem, p.114. No obstante, de forma equivocada, ROXIN, Claus. Autoría y dominio del hecho en derecho penal. tr. Joaquín Cuello Contreras y José Luis Serrano González de Murillo. Madrid-Barcelona: Marcial Pons, 1998. p. 268-269, pretende que quedan excluidos de su construcción los eventos de coacción y error, con el argumento -en el primer caso- de que a lo largo de los procesos de Nürnberg no se detectó "ni un solo caso" lo que, obvio es decirlo, no puede significar que no se haya acudido a ese medio; lo mismo, en casos de error, que descarta con un argumento todavía más sorprendente: "por lo general, sucederá que el autor directo puede en todo caso acallar la voz de su conciencia con la idea de la superior responsabilidad de quien da las órdenes", con lo que es la "voz de la conciencia" el único componente dogmático que justifica tal exclusión.

${ }^{62}$ Así, MEINI MÉNDEZ, Op. cit., nota 45, p. 64.

${ }^{63}$ Sobre ello, LÓPEZ MOJICA, Adriana Cristina. El concierto para delinquir y el tránsito legislativo suscitado por la Ley 1.121 de 2006. Bogotá: Universidad Sergio Arboleda, 2010. p. 79 y sigtes. 
jefe, pues se cree que se trata de una asociación individual que no dispone de la fungibilidad de sus miembros ${ }^{64}$.

En fin, no se debe olvidar que el Derecho penal propio de un Estado social y democrático de derecho no puede tolerar que los derechos de las personas -verdadero patrimonio de la cultura occidentalse pisoteen, por más que se trate de juzgar las más horrendas manifestaciones criminales; el imperio de la seguridad jurídica, no se olvide, demanda que a todo ciudadano se le escuche y se le venza en juicio y no se le condene al vaivén de los intereses políticos del momento o con acomodo de proclamas académicas de moda, al compás de las modernas cacerías de brujas medievales que se escudan tras de lo que no es un Derecho penal al servicio de la democracia.

\section{BibLIOGRAFíA}

AA. VV.: Lecciones de Derecho penal, Parte general. Bogotá: Universidad Externado de Colombia, 2002.

AMBOS, Kai. Dominio del hecho por dominio de voluntad en virtud de aparatos organizados de poder. tr. Manuel Cancio Meliá. Bogotá: Universidad Externado de Colombia. 1998.

La Parte general del Derecho penal internacional. trad. de Ezequiel Malarino. Bogotá: Editorial Temis, 2005.

. Dominio por organización. Estado de la discusión. En: Derecho penal contemporáneo: Revista Internacional. Bogotá: Legis, 2007, no. 19. p. 5-50.

-------. Tatherrschaft durch Willensherrschaft kraft organisatorischer Machtapparate. Eine kristische Bestandsaufnahme und weiterführende Ansätze. En: Goldammer's Archiv für Strafrecht, no. 5. Heidelberg: R. v. Decker, 1998. p. 226-245.

Principios e imputación en el Derecho penal internacional. 1 ed. Barcelona: Atelier Libros S. A., 2008.

-------. Imputación de crímenes de los subordinados al dirigente. Un estudio comparado. Bogotá: Editorial Temis, 2008.

-------. Politische und rechtliche Hintergründe des Urteils gegen den ehem. peruanischen Präsidenten Alberto Fujimori. En: Zeitschrift für Internatiomale Strafrechtsdogmatik, año 4, 2009, no. 11 p. 552-564. [en línea] «http:/ / www.zis-online.com» [citado en diez de diciembre 2013].

${ }^{64}$ Cfr. ROXIN, Op. cit., nota 60, p. 276; como él, POSADA ECHAVARRÍA, Op. cit., nota 24, p. 39-40. 
(coord.). Imputación de crímenes de los subordinados al dirigente. Un estudio comparado. Bogotá: GTZ/Fiscalía, Embajada de la República Federal de Alemania. Editorial Temis, Georg-August-Universität Göttingen, 2008.

AMBOS, Kai; GRAMMER, Christoph. Dominio del hecho por organización. La responsabilidad de la conducción militar argentina por la muerte de Elisabeth Käsemann. En: Revista Penal, no. 12; s/1, La Ley, 2003, p. 1141; también, En: Revista de Derecho Penal y Criminología, no 77. Bogotá: Universidad Externado de Colombia, 2005. p. 103-130.

AMBOS, Kai; MALARINO, Ezequiel; ELSNER, Gisela (ed.). Jurisprudencia Latinoamericana sobre Derecho Penal Internacional. Con un informe adicional sobre la jurisprudencia italiana. Montevideo: Georg-AugustUniversität Göttingen/Konrad Adenauer Stiftung, 2008. [en línea] «http://lehrstuhl.jura.unigoettingen.de/kambos/Person/doc/ JURISPRUDENCIA\%20LATINOAMERICANA\%20final.pdf» [citado en diez de diciembre 2013].

ARAMBURO CALLE, Maximiliano Alberto. La delincuencia en la empresa: problemas de autoría y participación en delitos comunes. En: Nuevo Foro Penal, no. 68. Medellín: Universidad Eafit, 2005. p. 93-144.

BERNATE OCHOA, Francisco. La imposibilidad de la aplicación de la autoría mediata por dominio funcional de aparatos de poder en el sistema legal colombiano. En: Revista internacional Derecho penal contemporáneo, no. 36. Bogotá: Legis, julio-septiembre 2011. p. 29-61.

La imposibilidad de la aplicación de la autoría mediata por dominio funcional de aparatos de poder en el sistema legal colombiano y los delitos de constreñimiento a delinquir y de inducción a delinquir como posibles fórmulas de solución. En: Serie documentos, no. 60. Bogotá: Universidad del Rosario, 2011.

BERTONI, Eduardo Andrés. Autoría mediata por aparatos organizados de poder: Antecedentes y aplicación práctica. En: MACEDO, Francisco (Coord.) Los caminos de la justicia penal y los derechos humanos. Lima: Instituto de Democracia y Derechos Humanos, Pontificia Universidad Católica del Perú, abril de 2007. p. 1-10. [en línea]. «http:/ /www.dplf.org/ uploads/1191421825.pdf» [citado en diez de diciembre de 2013].

BOLEA BARDÓN, Carolina. Autoría mediata en Derecho penal. Valencia: Tirant lo Blanch, 2000.

CADAVID LONDOÑO, Paula. Coautoría en aparatos organizados de poder de carácter delincuencial. Bogotá: Grupo Editorial Ibáñez- Universidad de los Andes, 2013.

CASTILLO GONZÁLEZ, Francisco. Autoría y Participación en el Derecho penal. San José: Editorial Jurídica Continental, 2006. 
CORTE SUPREMA DE JUSTICIA, SALA DE CASACIÓN PENAL. Sentencia de siete de marzo de 2007, Magistrado Ponente: Javier Zapata Ortiz, radicado: 23825.

-------. Sentencia de ocho de agoto de 2007, Magistrada Ponente: María del Rosario González de Lemos, radicado: 25974.

--------. Sentencia de doce de septiembre de 2007, Magistrado Ponente: Magistrado ponente: Augusto J. Ibáñez Guzmán, radicado: 24448.

Sentencia de dos de septiembre de 2009, Magistrado Ponente: Yesid Ramírez Bastidas, radicado: 29221.

-------. Sentencia de tres de diciembre de 2009, sin Magistrado Ponente, radicado: 32672 .

-------. Sentencia de 9 de diciembre de 2009, sin Magistrado Ponente, radicado: 28779 .

Sentencia de única instancia de 23 de febrero de 2010, sin Magistrado Ponente, radicado: 32805 .

- Sentencia de única instancia de doce de mayo de 2010, sin Magistrado Ponente, radicado: 29200 .

Sentencia de única instancia de catorce de septiembre de 2011, Magistrado Ponente: Alfredo Gómez Quintero, radicado: 32000.

-------. Auto de 26 de septiembre de 2012, Magistrado Ponente: Luis Guillermo Salazar Otero, radicado: 38250.

Auto de 22 de mayo de 2013, Magistrado Ponente: Gustavo Enrique Malo Fernández, radicado: 40830.

Auto de doce de febrero de 2014, Magistrado Ponente: Gustavo Enrique Malo Fernández, radicado: 40214.

DE LA CUESTA ARZAMENDI, José Luis. El Derecho penal ante la criminalidad organizada. Nuevos retos y límites. En: VALCÁRCEL LÓPEZ, Marta; GUTIÉRREZ ALVIZ Y CONRADI, Faustino (coord.). La cooperación internacional frente a la criminalidad organizada. Sevilla: Universidad de Sevilla, 2001, p. 85-126.

FARFÁN MOLINA, Francisco Javier. La masacre de machuca. Autoría mediata a través de aparatos organizados de poder. En: Revista Fallos y Conceptos, no. 8. Bogotá: Instituto de Estudios del Ministerio Público, Imprenta Nacional, 2006. 140 p.

GARCÍA VITOR, Enrique. La tesis del «dominio del hecho a través de los aparatos organizados de poder». En: BALCARCE, Fabián I. et al. Nuevas 
formulaciones en las Ciencias penales: homenaje a Claus Roxin. Córdoba: Facultad de Derecho y Ciencias Sociales, Universidad Nacional de Córdoba, 2001, p. 327-348.

HERNÁNDEZ NORIEGA, Alexandra; CABALLERO RODRÍGUEZ, Juan Pablo; ARANGO ZAMBRANO, María del Rosario. Reflexiones sobre la aplicabilidad de la «teoría de autoría mediata en aparatos organizados de poder» en Colombia. En: Revista de la Pontificia Universidad Javeriana Universitas Estudiantes In Memoriam Juan Rodrigo Villamil, no. 5. Bogotá, enero-diciembre, 2008. p. 65-84.

HEINE, Günter/WEIßER, Bettina. Täterschaft. En:SCHÖNKE-SCHRÖDER. Strafgesetzbuch. Kommentar. 29 ed. München: C. H. Beck, 2014. p. 517-538.

JAKOBS, Günther. Derecho penal. Parte general. Fundamentos y teoría de la imputación. tr. Joaquín Cuello Contreras y José Luis Serrano González Murillo. 1 ed. Madrid: Marcial Pons, Ediciones Jurídicas, S.A., 1995.

JOSHI JUBERT, Ujala. Sobre el concepto de organización en el delito de tráfico de drogas en la jurisprudencia del Tribunal Supremo. A propósito de la Sentencia del Tribunal Supremo de 19 de enero de 1995, ponente Excmo. Sr. Bacigalupo. En: Anuario de Derecho Penal y Ciencias Penales, tomo XLVIII, Fasc. II, mayo-agosto de 1995, Madrid: Ministerio de Justicia, 1995, p. 657-683.

JUZGADO TERCERO PENAL DEL CIRCUITO ESPECIALIZADO DE BOGOTÁ. Sentencia de primera instancia de nueve de junio de 2010, radicado: RUN 11001320700320080002500, contra el Coronel Luis Alfonso Plazas Vega.

JUZGADO ONCE PENAL DEL CIRCUITO ESPECIALIZADO DE BOGOTÁ. Sentencia de 30 de marzo de 2011, radicado: RUN 080013107001 2008-00027-00, contra Rodrigo Tovar Pupo alias 'Jorge 40'.

JUZGADO 51 PENAL DEL CIRCUITO DE BOGOTÁ. Sentencia de abril 28 de 2011, radicado: 2009-0203, contra el General Jesús Armando Arias Cabrales.

LÓPEZ MOJICA, Adriana Cristina. El concierto para delinquir y el tránsito legislativo suscitado por la Ley 1.121 de 2006. Bogotá: Universidad Sergio Arboleda, 2010.

MÁRQUEZ CÁRDENAS, Álvaro E. La autoría mediata en el Derecho penal. Bogotá: Ediciones Jurídicas Gustavo Ibáñez, 2002.

La autoría mediata en Derecho penal. Formas de instrumentalización, Bogotá: Ediciones Doctrina y Ley, 2009.

. Fundamento dogmático de la coautoría frente a la teoría del dominio del hecho. En: Diálogos de saberes: investigaciones en Derecho y ciencias sociales, no 22. Bogotá: Universidad Libre, 2005. p. 95-116. 
-------. La autoría mediata: autor detrás del autor en organizaciones criminales: narcotráfico, paramilitares, guerrilleras y mafiosas. En: Diálogos de saberes: investigaciones en Derecho y ciencias sociales, no. 23. Bogotá: Universidad Libre, 2005. p. 19-34.

MEINI MÉNDEZ, Iván Fabio. Problemas de autoría y participación en la criminalidad estatal organizada. En: Nuevo Foro Penal, no 68. Medellín: Universidad Eafit, 2005. p. 62-92.

El dominio de la organización en Derecho Penal. Lima, Palestra, 2008.

MUÑOZ CONDE. Francisco y GARCÍA ARÁN, Mercedes. Derecho penal, Parte general, 7 ed., Valencia, Tirant lo Blanch, 2007.

OLÁSOLO ALONSO, Héctor. Reflexiones sobre la doctrina de la empresa criminal común en Derecho penal internacional. En: Indret. Revista para el Análisis del Derecho. 2009, no. 3, p. 1-24.

Ensayos de Derecho penal y procesal internacional. Bogotá: Biblioteca Jurídica Diké. Ministerio de Justicia y del Derecho. Unión Europea: Instituto Iberoamericano de la Haya, 2011.

PASTOR, Daniel. El Derecho penal del enemigo en el espejo del poder punitivo internacional. En: CANCIO MELIÁ, Manuel y GÓMEZ-JARA DÍEZ, Carlos (Coords.). Derecho penal del enemigo: el discurso penal de la exclusión. vol. 2, Madrid: Edisofer; Buenos Aires-Montevideo: B de F, 2006, p. $475-522$.

POSADA ECHAVARRÍA, Plinio. Una visión del «dominio de la voluntad por organización» y su aproximación al Derecho penal colombiano. En: Nuevo Foro Penal. Bogotá: Temis-Universidad de Antioquia, 2000, no. 62, p. 38-40.

REYES CUARTAS, José Fernando. La autoría mediata con aparatos organizados de poder. En: Derecho Penal y Criminología, no. 75. Bogotá: Universidad Externado de Colombia, 2004. p. 135-157.

RIVERA LLANO, Abelardo. Derecho penal posmoderno. 1 ed. Bogotá: Temis, 2005.

ROXIN, Claus. Täterschaft und Tatherrschaft, 8 ed. Berlin, New York: Walter de Gruyter, 2006.

Autoría y dominio del hecho en Derecho penal. tr. Joaquín Cuello Contreras y José Luis Serrano González de Murillo. Madrid-Barcelona: Marcial Pons, 1998.

El dominio de organización como forma independiente de autoría mediata. Conferencia pronunciada el 23 de marzo de 2006 en la clausura del curso de Doctorado Problemas Fundamentales del Derecho Penal y la 
Criminología de la Universidad Pablo de Olavide, Sevilla. [en línea] «http:/ / www.iustel.com/v2/revistas/» [citado en diez de diciembre de 2013].

Strafrecht. Allgemeiner Teil. Besondere Erscheinungsformen der Straftat, t. II. München: C. H. Beck, 2003.

SÁNCHEZ HERRERA, Esiquio Manuel. La autoría en los aparatos organizados de poder. La situación en la jurisprudencia nacional. En: Huellas. Reflexiones sobre el Derecho penal, no. 72, julio de 2011. Bogotá: Fiscalía General de la Nación. p. 121-136.

SCHILD, Wolfgang. Täterschaft. En: KINDHÄUSER, Urs; NEUMANN, Ulfrid; PAEFFGEN, Hans-Ulrich. Nomos Kommentar zum strafgesetzbuch, t. I. 3 ed. Baden Baden: Nomos Verlag, 2010. p. 990-1077,

SCHÜNEMANN, Bernd. El dominio sobre el fundamento del resultado: base lógico-objetiva común para todas las formas de autoría. tr. Mariana Sacher. En: Derecho penal y criminología, 2004, no. 75, Bogotá: Universidad Externado de Colombia, 2004. p. 13-25.

-------. El tempestuoso desarrollo de la figura de la autoría mediata, trad. de María Carolina Palma Vargas: En: Derecho penal y criminología, 2004, no. 75, Bogotá: Universidad Externado de Colombia, 2004, p. 27-42.

milenio. Madrid: Tecnos, 2002.

. Aspectos Puntuales de la Dogmática Jurídico-penal. Bogotá: Ibáñez/ Universidad de Santo Tomás, 2007.

SUÁREZ LÓPEZ, Carlos Alberto. Aproximación a la problemática de la responsabilidad penal de los jefes de las organizaciones criminales. En: Huellas. Reflexiones sobre el Derecho penal, no. 72. Bogotá: Fiscalía General de la Nación, julio de 2011, p. 5-62.

SUÁREZ SÁNCHEZ, Alberto. Autoría y Participación. 2 ed. Bogotá: Universidad Externado de Colombia, 1998.

Autoría y Participación. 3 ed. Bogotá: Universidad Externado de Colombia, 2007.

TRIBUNAL SUPERIOR DEL DISTRITO JUDICIAL DE BOGOTÁ, SALA DE JUSTICIA Y PAZ. Sentencia de dos de diciembre 2 de 2010, radicado: RUN 110016000253200680281, en contra de Jorge Iván Laverde Zapata, alias 'El Iguano'.

TRIBUNAL SUPERIOR DE DISTRITO JUDICIAL DE BOGOTÁ, SALA PENAL. Sentencia de segunda instancia, de 30 de enero de 2012, radicado: RUN 110010704003200800025 09, contra el Coronel retirado Alfonso Plazas Vega. 
VELÁSQUEZ NIÑO, Jorge. La autoría mediata por medio de estructuras organizadas de poder: el caso colombiano. En: Realidades y Tendencias del Derecho en el Siglo XXI. t. III. Bogotá: Universidad Javeriana/Temis, 2010. p. 259-284.

VELÁSQUEZ VELÁSQUEZ, Fernando. Manual de Derecho penal, Parte general. 1 ed. Bogotá: Temis, 2002.

. Manual de Derecho penal, Parte general. 2 ed. Bogotá: Temis, 2004.

Manual de Derecho penal, Parte general. 3 ed. Medellín: Editora Jurídica Comlibros, 2007.

-------. Manual de Derecho penal, Parte general. 4 ed. Bogotá: Ediciones jurídicas Andrés Morales, 2010.

Manual de Derecho penal, Parte general. 5 ed. Bogotá: Ediciones jurídicas Andrés Morales, 2013.

Derecho penal. Parte general. 1 ed. Bogotá: Temis, 1994.

-------. Derecho penal, Parte general. 4 ed. Medellín: Editora Jurídica Comlibros, 2009.

Los líderes paramilitares: ¿autores mediatos por medio de aparatos criminales organizados de poder? En: Libro Homenaje: Realidades y tendencias del Derecho en el siglo XXI, Derecho penal. Tomo III. Bogotá: Universidad Javeriana, Temis, 2010. p. 231-258.

Los líderes paramilitares: ¿autores mediatos por medio de aparatos criminales organizados de poder? En: Revista de Derecho Penal, Imputación, causalidad y Ciencia-III. Buenos Aires: Rubinzal-Culzoni, 2011. p. 79-116.

-----. Los aparatos criminales organizados de poder. En: Cuadernos de Derecho no 4, 2010, p. 173-190. Bogotá: Universidad Sergio Arboleda [En línea] «http://www.usergioarboleda.edu.co/derecho_penal/cuadernosde-derecho-penal4.htm» [citado en diez de diciembre de 2013].

-------. Justicia internacional penal. Presente y futuro. En: Jueces para la democracia. no. 74,2012 . p. 375 y sigtes.

La concurrencia de personas en el delito y los aparatos criminales organizados de poder. En: Derecho, Universalidad y conocimiento: Homenaje a Miguel Valadez Reyes. México: Universidad de Guanajuato, 2010. p. 136-137.

ZAFFARONI, Eugenio Raúl; ALAGIA Alejandro y SLOKAR Alejandro. Derecho penal, Parte general. 2 ed. Buenos Aires: Ediar, 2002. 
